\title{
Fresh hypothermically stored amniotic allograft in the treatment of chronic nonhealing ulcers: a prospective case series
}

This article was published in the following Dove Press journal: Chronic Wound Care Management and Research

\author{
Matthew Sabo' \\ Sarah Moore ${ }^{2}$ \\ Raphael Yaakov ${ }^{2}$ \\ Bryan Doner ${ }^{3}$ \\ Keyur Patel ${ }^{3}$ \\ Thomas E Serena ${ }^{2}$ \\ 'The Foot and Ankle Wellness Center \\ of Western Pennsylvania, Ford City, \\ PA, USA; ${ }^{2}$ SerenaGroup ${ }^{\circledR}$, Hingham, \\ MA, USA; ${ }^{3}$ The Snyder Institute, \\ ACMH Hospital, Kittanning, PA, USA
}

Correspondence: Thomas E Serena SerenaGroup, Suite 18B, 175 Derby St, Hingham, MA 02140, USA

Tel +l 6179455225

Email serena@serenagroups.com
Introduction: Amniotic membranes have been used for a variety of surgical applications since the 1900s. Recent developments in the field of chronic wound care have accelerated and expanded their use. To date, there are over 70 amniotic products available, including dehydrated human amnion/chorion and cryopreserved human amnion. The integrity of these grafts, however, may be compromised during processing. Fresh hypothermically stored amniotic allograft (HSAM) may improve healing rates by preserving growth factors and living cells, including stem cells, as well as retaining the membrane's native structure.

Methods: Healing outcomes were evaluated in patients receiving HSAM for the treatment of chronic nonhealing ulcers. Relevant medical history was captured in addition to data on wound characteristics and measurements. Two venous leg ulcers and one postsurgical wound were treated with HSAM.

Findings: A significant reduction in wound size was observed for patients treated with HSAM. Overall, HSAM demonstrated a wound size reduction of $93.94 \%$ in 42 days. These results provide evidence that HSAM may reduce the long-term costs associated with the care of chronic ulcers by increasing the healing rate and lowering the risk of infection and complications.

Keywords: chronic wounds, regenerative medicine, wound care, amnion, hypothermically stored amniotic membrane

\section{Introduction}

Millions suffer from difficult to heal ulcers worldwide. The incidence of chronic ulcers is increasing rapidly, fueled by an aging population, rising incidence in obesity, diabetes, and venous insufficiency. Diabetic foot ulcers (DFUs), VLUs, and nonhealing postsurgical wounds are among the most frequently encountered ulcers in wound care practice. In the United States, over 4.3 million diabetic patients will develop a DFU in their lifetime, and 2.5 million individuals suffer from VLUs. ${ }^{1-4}$ DFUs add $\$ 9-\$ 13$ billion to the direct yearly cost associated with diabetes itself. ${ }^{5}$ The annual cost of VLUs is $\sim \$ 2.5-\$ 3.5$ billion. ${ }^{6}$ Nonhealing surgical wounds are also commonly seen in wound care clinics. Surgical wounds pose an increased risk for infection and contribute to the growing economic burden of wound care management.

In recent years, several clinical trials have been conducted to investigate products derived from human amniotic membranes (HAMs) as adjunctive therapies to accelerate wound healing. The HAM is the inner avascular layer of the placental basement membrane and is composed of conjoined amnion and chorion membranes. ${ }^{7}$ The amnion comprises of different layers - the epithelium, basement membrane, and stroma - and these layers 
further consist of three contiguous but distinct layers - the inner compact layer, the middle fibroblast layer, and the outermost spongy layer. The HAM has been shown to have anti-inflammatory, antifibrotic, antiangiogenic as well as antimicrobial properties. ${ }^{8}$ Research has confirmed that growth factors present in amniotic membranes can induce angiogenesis and human dermal fibroblast proliferation as well as recruit multiple stem cells relevant to wound repair and regeneration. ${ }^{9,10}$

A fresh hypothermically stored amniotic allograft (HSAM) may improve healing rates by preserving growth factors and living cells, including stem cells, as well as retaining the membrane's native structure. ${ }^{11,12}$ HSAM is aseptically processed and stored in a proprietary hypothermic storage solution using the Allofresh ${ }^{\mathrm{TM}}$ (Organogenesis, Canton, MA, USA) process. ${ }^{13}$

\section{Methods}

A case study was conducted to evaluate an HSAM (Organogenesis) in the treatment of chronic wounds. Information was collected on patient demographics, wound type, wound location, age of wound, comorbidities, previous treatments, and current treatments. All patients were informed of study procedures and consented to have their case details and any accompanying photographs published. Digital planimetry (ARANZ Medical, Christchurch, New Zealand) was used at each visit to record the wound surface area. Previous and current treatments were recorded. Two of the patients presented with VLU and one had a postsurgical wound.

The VLU patients had previously received compression, and one patient had also received negative pressure wound therapy. The one with a surgical wound had received a variety of previous therapies, including topical silver, Hydrofera Blue, and topical antibiotics. The age of the wounds for the VLUs were 2-3 weeks, while the surgical wound was 5 months. Comorbidities for the VLUs consisted of venous insufficiency, diabetes, arthritis, osteomyelitis to ulcer loca- tion, hypertension, and lymphedema. Comorbidities for the surgical wound patient consisted of arthritis and hypertension. The new treatment regimen consisted of HSAM covered with a knotted cellulose acetate fabric dressing (Adaptic ${ }^{\circledR}$; Acelity, San Antonio, TX, USA) and appropriate standard of care, including offloading, multilayer compression, and surgical debridement.

\section{Findings \\ Case I}

A 62-year-old patient presented to the wound clinic with a postop foot wound (nondiabetic), right foot dorsum. The duration of the wound was 5 months, with previous treatments consisting of topical antimicrobials. His comorbidities consisted of arthritis and hypertension. On day 0 , the wound area size measured $3.3 \mathrm{~cm}^{2}$, with $50 \%$ granulation, $10 \%$ fibrin, $40 \%$ slough, and a moderate amount of light red/pink serosanguineous drainage. Moderate edema was present. A $2.5 \mathrm{~cm} \times 2.5$ cm HSAM was applied and fixed in place using Steri-Strips ${ }^{\mathrm{TM}}$ (McKesson Medical-Surgical, Londonderry, NH, USA). On day 21 , the wound area reduced to $2.9 \mathrm{~cm}^{2}$, a $12.12 \%$ reduction. There was an increase in the percentage of granulation tissue as well. By day 42, the wound area size had reduced by $81.82 \%$ with $100 \%$ granulation, and healed on day 71 (Figure 1).

\section{Case 2}

A 57-year-old patient presented with a left lower extremity VLU on the medial malleolus. The wound had been present for 8 weeks. The treatment thus far consisted of compression and topical antimicrobials. His past medical history included chronic venous insufficiency, peripheral vascular disease, deep vein thrombosis, and hyperlipidemia. On day 0 , the wound area measured $0.3 \mathrm{~cm}^{2}$. HSAM $(2.5 \mathrm{~cm} \times 2.5 \mathrm{~cm})$ was applied and held in place with Steri-Strips ${ }^{\mathrm{TM}}$ (McKesson Medical-Surgical) and compression wrap. On day 7, the wound was completed closed with no drainage (Figure 2).
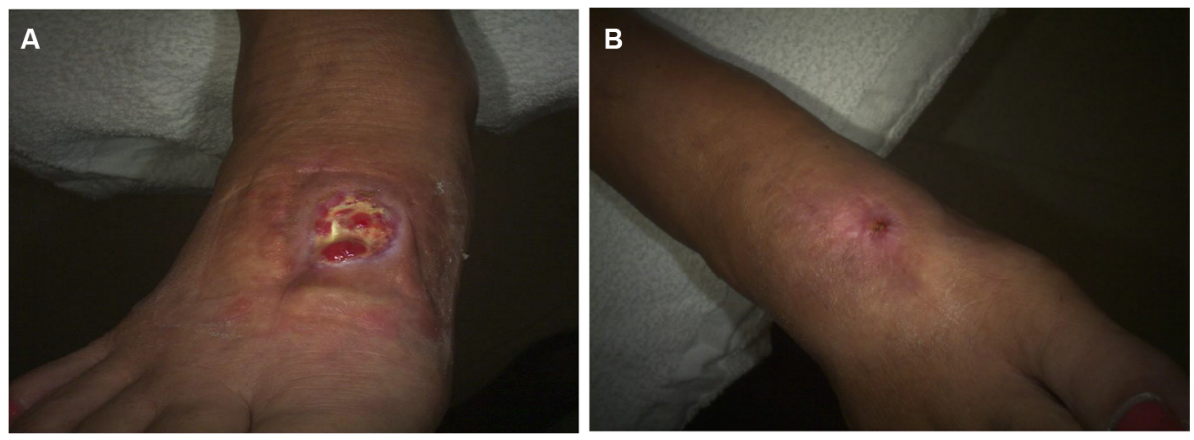

Figure I Case I surgical wound.

Note: (A) Day 0, $3.3 \mathrm{~cm}^{2}$; (B) day 7I, $0 \mathrm{~cm}^{2}$. 

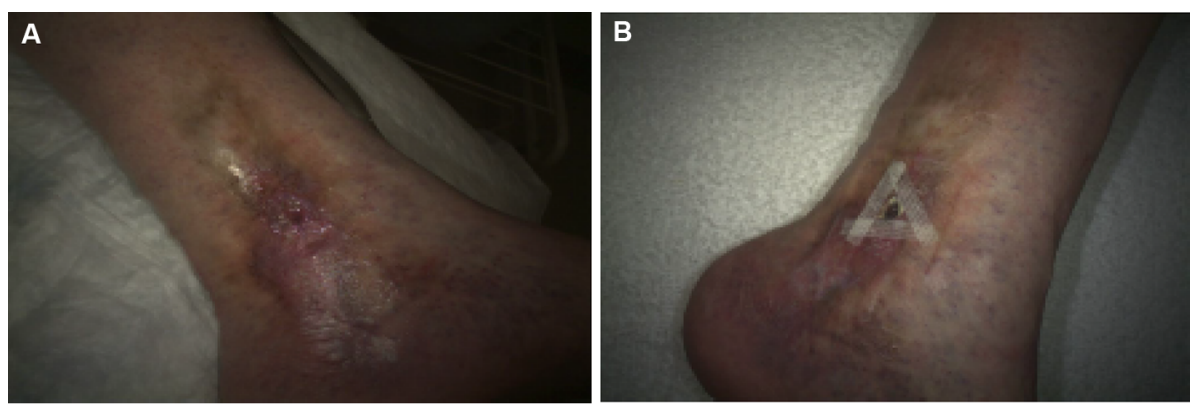

Figure 2 Case 2 venous leg ulcer.

Note: (A) Day 0, $0.3 \mathrm{~cm}^{2}$; (B) day $7,0 \mathrm{~cm}^{2}$.
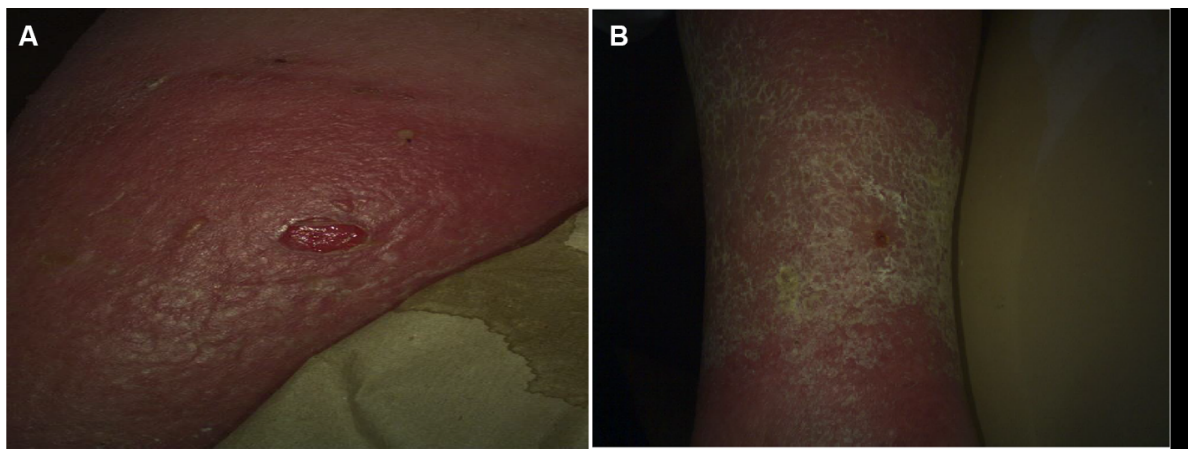

Figure 3 Case 3 venous leg ulcer.

Note: (A) Day 0, $1.0 \mathrm{~cm}^{2}$; (B) day $14,0 \mathrm{~cm}^{2}$.

\section{Case 3}

A 70-year-old patient presented with a VLU on the medial right lower extremity. The wound had been present for 2 weeks. The medical history obtained from this patient revealed hypertension, lymphedema, type II diabetes, and chronic venous insufficiency. At the time of HSAM $(2.5 \mathrm{~cm}$ $\times 2.5 \mathrm{~cm}$ ) application, the wound area measured $1.0 \mathrm{~cm}^{2}$. By day 7 , the wound area was reduced to $0.4 \mathrm{~cm}^{2}$, and by day 14, it achieved complete closure (Figure 3 ).

\section{Discussion}

Prompt treatment of chronic ulcers is essential in preventing complications, reducing the cost of care, and lessening the economic burden on the health care system. In clinical studies, amniotic membranes have been shown to be effective in promoting healing in chronic wounds. ${ }^{14,15}$ Prior products consisted of dehydrated products. We postulated that fresh amniotic membrane would demonstrate even greater effect. Prior to embarking on large expensive clinical trials, we tried the fresh amniotic product on a few selected patients. Results from this study suggested that HSAM may be an effective treatment option for management of VLUs and other nonhealing wounds. HSAM offers a new treatment alternative to promote healing in chronic wounds. ${ }^{13}$ This membrane con-

tains numerous growth factors and cytokines. These growth factors are found to be released over an extended period and result in increased cellular migration, proliferation, and remodeling. ${ }^{13}$ Moreover, HSAM may reduce the long-term costs associated with the care of chronic ulcers by increasing the healing rate and lowering the risk of infection and complications This pilot case series was subsequently used to inform larger DFU and VLU trials that are ongoing at the time of this writing.

\section{Acknowledgment}

The findings from these case series were previously presented at the SAWC Fall conference, Las Vegas, NV, October 7-9, 2016.

\section{Disclosure}

The authors report no conflicts of interest in this work.

\section{References}

1. Abbott CA, Carrington AL, Ashe H, et al; North-West Diabetes Foot Care Study. The North-West Diabetes Foot Care Study: incidence of, and risk factors for, new diabetic foot ulceration in a community-based patient cohort. Diabet Med. 2002;19(5):377-384.

2. Centers for Disease Control and Prevention (CDC). Lower extremity disease among persons aged $\geq 40$ years with and without diabetes - United States, 1999-2002. MMWR Morb Mortal Wkly Rep. 2005;54(45):1158-1160. 
3. Lauterbach S, Kostev K, Kohlmann T. Prevalence of diabetic foot syndrome and its risk factors in the UK. JWound Care. 2010;19(8):333-337.

4. O'Donnell TF, Passman MA, Marston WA, et al. Management of venous leg ulcers: clinical practice guidelines of the Society for Vascular Surgery ${ }^{\mathbb{R}}$ and the American Venous Forum. J Vascu Surg. 2014;60(2):3S-59S.

5. Rice JB, Desai U, Cummings AK, Birnbaum HG, Skornicki M, Parsons NB. Burden of diabetic foot ulcers for Medicare and private insurers. Diabetes Care. 2014;37(3):651-658.

6. Sen CK, Gordillo GM, Roy S, et al. Human skin wounds: a major and snowballing threat to public health and the economy. Wound Repair Regen. 2009;17(6):763-771.

7. Koob TJ, Lim JJ, Massee M, Zabek N, Denozière G. Properties of dehydrated human amnion/chorion composite grafts: implications for wound repair and soft tissue regeneration. J Biomed Mater Res B Appl Biomater. 2014;102(6):1353-1362.

8. Malhotra C, Jain AK. Human amniotic membrane transplantation: different modalities of its use in ophthalmology. World J Transplant. 2014;4(2):111-121.

9. Maxson S, Lopez EA, Yoo D, Danilkovitch-Miagkova A, Leroux MA. Concise review: role of mesenchymal stem cells in wound repair. Stem Cells Transl Med. 2012;1(2):142-149.
10. Chen L, Tredget EE, Wu PY, Wu Y. Paracrine factors of mesenchymal stem cells recruit macrophages and endothelial lineage cells and enhance wound healing. PLoS One. 2008;3(4):31886.

11. Niknejad H, Peirovi H, Jorjani M, Ahmadiani A, Ghanavi J, Seifalian AM. Properties of the amniotic membrane for potential use in tissue engineering. Eur Cell Mater. 2008;15:88-89.

12. Cooke M, Tan E, Mandrycky C, He H, O'Connell J, Tseng S. Comparison of cryopreserved amniotic membrane and umbilical cord tissue with dehydrated amniotic membrane/chorion tissue. $J$ Wound Care. 2014;23(10):465-476.

13. McQuilling JP, Vines JB, Mowry KC. In vitro assessment of a novel, hypothermically stored amniotic membrane for use in a chronic wound environment. Int Wound J. 2017;14:993-1005.

14. ElHeneidy H, Omran E, Halwagy A, Al-Inany H, Al-Ansary M, Gad A. Amniotic membrane can be a valid source for wound healing. Int $J$ Womens Health. 2016;8:225-231.

15. Laurent I, Astère M, Wang KR, Cheng Q, Li QF. Efficacy and time sensitivity of amniotic membrane treatment in patients with diabetic foot ulcers: a systematic review and meta-analysis. Diabetes Ther. 2017;8(5):967-979.
Chronic Wound Care Management and Research

\section{Publish your work in this journal}

Chronic Wound Care Management and Research is an international, peer reviewed, open access, online journal publishing original research, reviews, editorials, and commentaries on the causes and management of chronic wounds and the major issues related to chronic wound management. Topics also include chronic wounds as comorbidities to other

\section{Dovepress}

conditions, patient adherence to therapy, and the economic burden of chronic wounds. The manuscript management system is completely online and includes a very quick and fair peer review system, which is all easy to use. Visit http://www.dovepress.com/testimonials.php to read real quotes from published authors.

Submit your manuscript here: https://www.dovepress.com/chronic-wound-care-management-and-research-journal 